\title{
Simple and Inexpensive Method to Modify Bee Honey Extractor with Moving Baskets to Radial Extractor is Easy to Jaw and Installion, or with Out Baskets Zohairy, A. M. \\ Bee Research Dept., Plant Protection Res. Inst. Agric. Res. Center, Egypt.
}

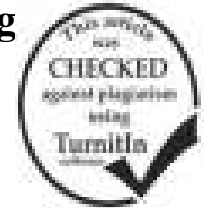

\section{ABSTRACT}

This study was carried out on honey extractor with eight moving baskets to evaluate three methods for modification of this extractor (The most prevalent in Egypt) to radial extractor as following:- The first method, (1) Possibility to temporary modify of honey extractor with moving baskets to radial extractor, with retaining all components and parts of this extractor, by fixing the moving basket in the direction of the extractor radius by iron wire is n-shaped. So the honey are extracted from both sides of the honeycomb once at the same time. (2) The honeycomb head should be placed beside the moving axis of the basket, so do not break the combs. The second method, modify of the extractor with moving baskets to radial extractor is easy to jaw and installation and have twice the number of baskets, by making three circles of iron for fixed the baskets in the direction of the extractor radius, (1) With the present number of 8 baskets only, will save more than twice the time. (2) With the number twice of 16 baskets, it provides four times for the extractor with moving baskets. The third method, the modification to radial extractor without baskets, by making three circles of iron for fixed the combs (16 combs) in the direction of the extractor radius. The results showed that, the first method is a simple and inexpensive, honey combs don't broken and providing twice the time, the honeycomb head should be placed beside the moving axis of the basket, so do not break the combs while the second method which is easy to jaw and installation and have double number of baskets. The third method, the extractor is very light, it provides four times comparing with the extractor have moving baskets, and all combs were intact and unbroken.

\section{INTRODUCTION}

Extracting honey is an arduous and stressful process. It needs a lot of trained workers to accomplish it in a faster and short time. Extractors are either tangential or radial depending on how the combs are put into the basket. There are many types as:-

1 - The extractor with the moving baskets (Cowan extractor) is the most prevalent in Egypt, it consists of four or six or eight baskets according to the extractor capacity. When the rotation, the honey is extracted from the outer side of the comb near the extractor wall, when the complete extraction, stop the rotation to change the situation the combs, then return the rotation again to extraction the other side of the comb in the same way. Wafa, (1959). Hassanein, (1960). Abdellatif, (1994). El-Banby, (1994). Often, the new combs are broken when honey extraction from the first side of the combs. Also, the combs which containing the pollen break down. When the first side is extracted, the rotation is stopped and the baskets are wrapped on the other side and then rotated again to extract other side, this requires more time and effort.

2 - The electric radial extractor is used in largest apiaries, it consists of twelve baskets even more than fifty baskets, because it heavy it works by electric motor power. The baskets are fixed in the direction of the extractor radius, thus, the honey extraction from both sides of the comb at one batch once at the same time. The amount of work and time become reduced in the radial type, but difficult to clean easily becose the baskets are fixed, these types are expensive, Wafa, (1959). Hassanein, (1960). Abdellatif, (1994). El-Banby, (1994). Hussein, (2004). El-Ansuaary, (2007).

3 - The honey extractor with touching baskets:- The honey combs are placed in contact with the walls of the inner basket. The honey is extracted by the centrifugal force from the outer side of the comb touching the wall. The rotation is then stopped and the comb is go out and the other side of the comb is turn round to the wall. This extractor is used by small beekeepers for its light weight and simplicity is often administered manually and sometimes electrically. Abdellatif, (1994). Hussein, (2004). El-Ansuaary, (2007). It takes a lot of time and effort.

4 - Pivotal extractor:- It consists of eight cylindrical baskets, each basket individually revolving around its own axis, while all baskets revolve around the central axis of the extractor. Honey is extracting from both sides of the comb at the same time, too expensive and often not found in Egypt. Wafa, (1959). Abdellatif, (1994). El-Banby, (1994). El-Ansuaary, (2007). It is very expensive, complex and therefore not spread in Egypt.

5 - Self-Reversible Extractor:- When completed the extraction of the first side of comb, by control key which move right or left change the place of the comb automatically (self-reversible)to another side. Each comb put in special basket to be vertical during the extraction. El-Ansuaary, (2007). It is very expensive.

Hassan and Aly (1997) mentioned that honey extracting manner affect longevity, behavior and production capacity of honeybee. The use of radial extractor is less harmful than the use of the extractor with the moving baskets. The exposure time of sealed brood combs should reduce to the damage of the extraction procedures, for get strong colonies.

Hassanein, (1960) mentioned that hexagonal are tilted up at a $14^{\circ}$ angle to prevent larvae from falling out of the hexagonal opening.

For this many problems of extractor with moving baskets were this work for modify the honey extractor with moving baskets to radial extractor, with exploitation of the existing extractor and available have many beekeepers.

\section{MATERIALS AND METHODS}

Experiments were carried out in a private apiary, El-Manzala district Center, El-Dakahlia Governorate, Egypt, on May 2018 during honeycombs extraction of Egyptian Clover honey. The extractor has eight moving baskets, was used after modification. 
Where the extractor with moving baskets (Cowan Extractor) is the most prevalent in Egypt. It consists of two or four or six or eight baskets, whine it works the honey extracted from the outer face of the honeycomb nearer from the extractor wall. When extraction is finished, it stops rotating to change the position of the baskets with the combs and then it works again to extraction the honey from the other side in the same previous way.

First : - In this study three methods for modification of the extractor with moving baskets to radial extractor as following :-

The first method: - The temporary modify of honey extractor with moving baskets to radial extractor while retaining all components and parts of the extractor:-

1 - Description of an iron wire which fixes the moving basket in the direction of the extractor radius, for temporary modify:- Eight iron wires with $1 \mathrm{~cm}$. thickness, each one is formed of a letter $n$, each arm is $15 \mathrm{~cm}$. in length and the distance between them is 2.1 $\mathrm{cm}$, each basket have one, as (Fig.1).

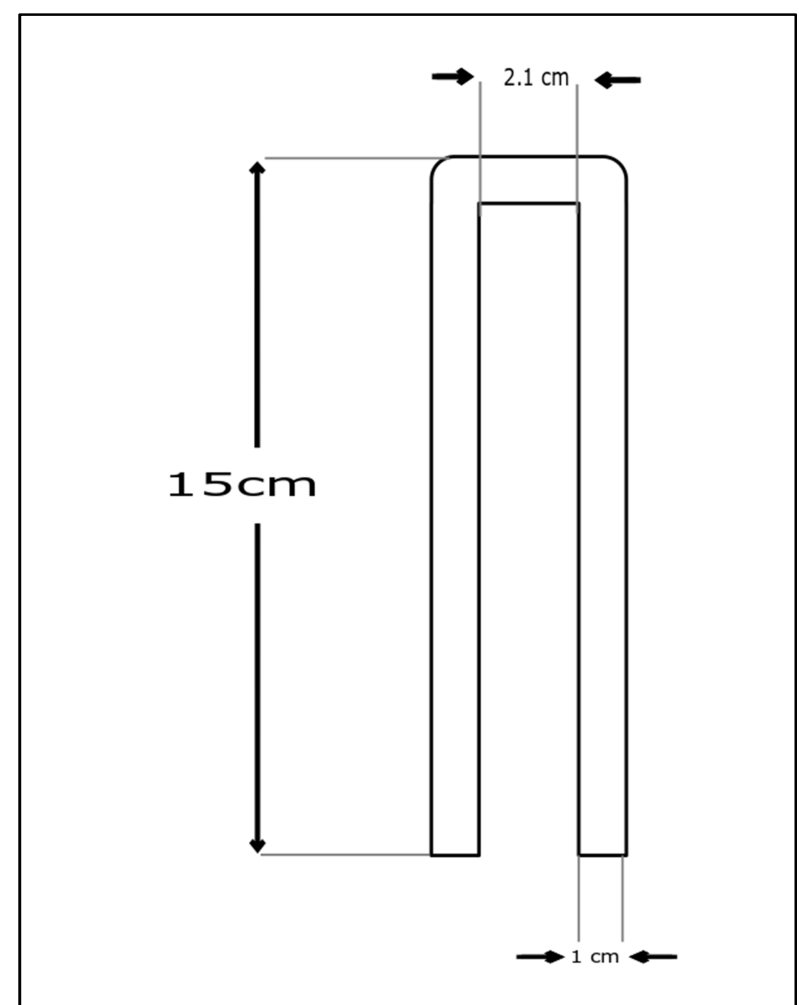

Fig. 1. The temporary modify, by an iron wire with $1 \mathrm{~cm}$. thickness, it is formed of a letter $\mathrm{n}$, each arm is $\mathbf{1 5}$ $\mathrm{cm}$. in length and the distance between them is $\mathbf{2 . 1}$ cm., each basket have one.

2 - Principal idea of the temporary modify: - While retaining all components and parts of the extractor, by fixing the moving basket in the direction of the extractor radius by the iron wire (the previously mentioned), it is placed on the upper iron of moving chassis (which carry the basket) so that the two arms enter inside the end of the basket, next to the thin bar of the honeycomb (in the space between the honeycomb and the end of the basket).

\section{3 - The operation:-}

The present used extractor is the extractor with the moving baskets (Cowan extractor), it has eight baskets.
After putting eight from un sealed honey combs inside the baskets with normal method of the extractor with the moving baskets, each basket turn of nearly 90 degree, until it becomes in the direction of the extractor radius, then it fix on this position, by putting this an iron wire the previously mentioned (Fig 1), between the honeycomb and end of the basket, and so the all the other baskets. The extractor is rotated by the hand. When the honey is extracted from the honeycombs, stop the rotation of the extractor, remove the iron wire, each basket turn of nearly 90 degree until it becomes next to the extractor wall, go out empty honeycombs and replace them with other un sealed honeycombs are un sealed, and so on, thus, the honey is extracted from both sides of the honeycombs once at the same time.

4 - Calculation the time needed to extraction a batch (eight honeycombs) of honeycombs by the extractor with the moving baskets (before modify), then calculation the time needed to extraction other a batch (eight honeycombs) of honeycombs by this extractor after modify and recording this time, then comparison between both this the times before the modify and after this the temporary modify, for providing more of the time double during the extraction.

The second method: - modify of the extractor with moving baskets to radial extractor which is easy to jaw and installation and have twice the number of baskets: -

This modify of extractor has eight baskets, this is done by making three circles of iron, and the two ends of each circle are closed by screw bolt: -

(1) The first circle $(5 \times 15 \mathrm{~mm})$, and $(5 \mathrm{~mm})$ to upper, the perimeter is about $270 \mathrm{~cm}$. divided into 16 parts, in each part an iron finger (diameter $0.5 \mathrm{~cm}$, length $5 \mathrm{~cm}$ ) is welded, fingers to up for carrying the baskets bottom, (Fig. 2). This circle is placed in the bottom of the extractor as it passes between the down fingers (which carry the baskets of extractor with moving baskets) and the moving chassis.

(2) The second circle is an iron wire with $5 \mathrm{~mm}$ diameter, it have the same previous perimeter, and the fingers are fixed in the same previous way, but the direction is downwards, for fixed the baskets tops, (Fig. 3). This circle is must pass between the upper fingers (of the baskets of extractor with moving baskets) and the moving chassis.

(3) The third circle $(5 \times 15 \mathrm{~mm})$, and $(5 \mathrm{~mm})$ to upper, this circle is placed for carrying the end bottom of the baskets. The perimeter of the circle is divided into eight equal parts. In each part, two fingers are welded to up with a thickness of $5 \mathrm{~mm}$ and the distance between them is $25 \mathrm{~mm}$. ( $35 \mathrm{~mm}$. with thickness of two fingers ), (Fig. 4).

This can be used with the present number of baskets ( 8 baskets), placing a basket inside a finger, leaving the next finger, then placing another basket, etc ... (for the first and second circle), placing the two fingers of the third circle inside the end bottom of the basket.

New baskets can be made with the same number of baskets as there are, thus, the number of baskets (16 baskets) become twice the number of baskets before modification, and baskets are placed in all the fingers of the first, second and third circles. 


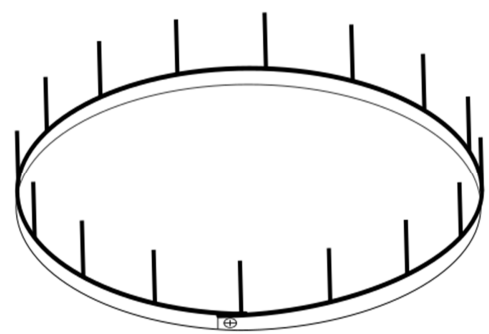

Fig. 2. The first circle $(5 \times 15 \mathrm{~mm})$, the ends are closed with a screw, thickness of $5 \mathrm{~mm}$ to the top, the circumference of the circle is about $270 \mathrm{~cm}$ for extractor have eight baskets, and the circle is divided into 16 parts, one finger (thickness 5 $\mathrm{mm}$, length $5 \mathrm{~cm}$ ) is welded on each part, for carrying the basket.

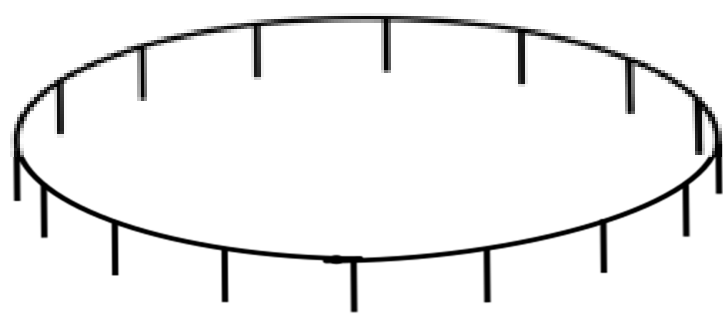

Fig. 3. The second circle is a $5 \mathbf{~ m m}$ diameter iron wire. The ends are closed with a screw, it is the same previous length, and the fingers (thickness 5 $\mathrm{mm}$, length $5 \mathrm{~cm}$ ) are fixed in the same previous way, but the direction is downward, for fixing the basket from the top.

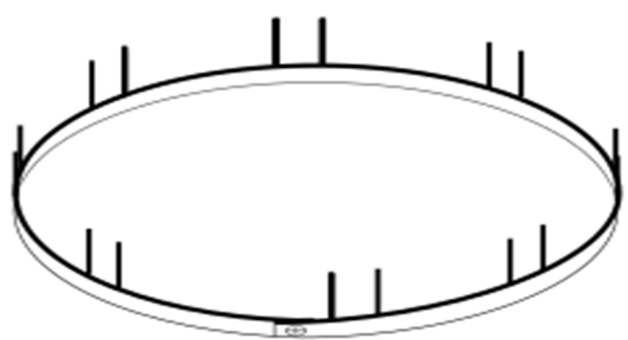

Fig. 4. Third circle (5 x $15 \mathrm{~mm})$, thickness of $5 \mathrm{~mm}$ to the top, the ends are closed with a screw, the circumference of the circle is divided to eight equal parts, two fingers (thickness $5 \mathrm{~mm}$, length $5 \mathrm{~cm}$ ) are welded and the distance between them is $25 \mathbf{~ m m}$, for carrying the basket bottom end.

The third method : - Modification of the extractor with moving baskets to radial extractor without baskets: - As follows: This is done by making three circles of iron, closing the ends of each circle with screw bolt: - (1) The first circle (thickness $5 \mathrm{~mm} \mathrm{x}$ width $15 \mathrm{~mm}$ ) and circumference of the circle about $270 \mathrm{~cm}$ so that the thickness of $5 \mathrm{~mm}$ to upper, it fix the extractor bottom to carry the combs, and pass between the lower fingers (carrying baskets of extractor with moving baskets ) and moving chassis, circumference of this circle is divided into equal parts (16 part) . Iron wire with a diameter of $5 \mathrm{~mm}$ and length $11 \mathrm{~cm}$ (U-shaped $3+5+3 \mathrm{~cm}$ ) is welded and fixed in each part so that it is perpendicular to the width (15 mm) to carry and fixed the comb head, (Fig. 5). (2) The second circle is a $5 \mathrm{~mm}$ diameter iron wire. The circumference of the circle is about $270 \mathrm{~cm}$. The circumference is divided into 16 parts. Each part is fixed with a $3 \mathrm{~mm}$ wire in the shape of a rectangle $(5 \mathrm{~cm} \times 25$ $\mathrm{cm}$ ), for place the comb inside this rectangle, this circle is fixed in the moving chassis at a height of $41 \mathrm{~cm}$ from the first circle, and the ends of the rectangles is fixed with a small circle from wire, (Fig. 6).(3) The third circle (thickness $5 \mathrm{~mm} \times 18 \mathrm{~mm}$ width), thickness $5 \mathrm{~mm}$ to upper and circumference $145 \mathrm{~cm}$ and its center is the same center of the extractor, to carry the comb end down, the width of this circle $18 \mathrm{~mm}$ is higher than the width of the first circle $15 \mathrm{~mm}$ until the comb is slightly oblique towards the extractor wall, (Fig. 7).

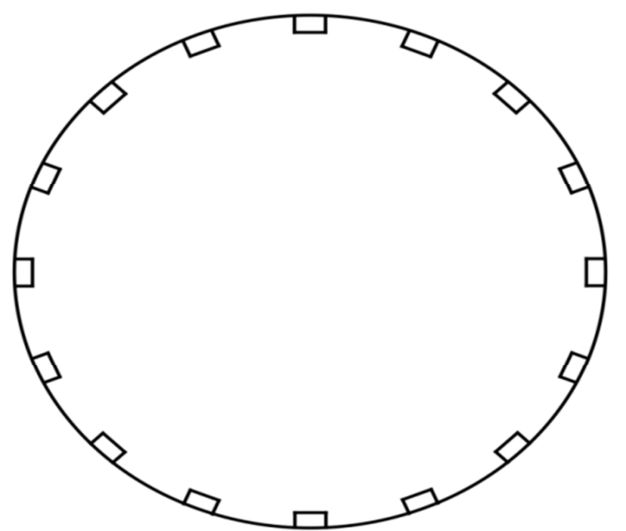

Fig. 5. The first circle (thickness $5 \mathrm{~mm} x$ width $15 \mathrm{~mm}$ ) and circumference of the circle about $270 \mathrm{~cm}$ so that the thickness of $5 \mathrm{~mm}$ to upper, it fix the extractor bottom to carry the combs, and pass between the lower fingers (carrying baskets of extractor with moving baskets) and moving chassis, circumference of this circle is divided into equal parts (16 part) . Iron wire with a diameter of $5 \mathrm{~mm}$ and length $11 \mathrm{~cm}$ (U-shaped $3+5+3$ $\mathrm{cm})$ is welded and fixed in each part so that it is perpendicular to the width $(15 \mathrm{~mm})$ to carry and fixed the comb head.

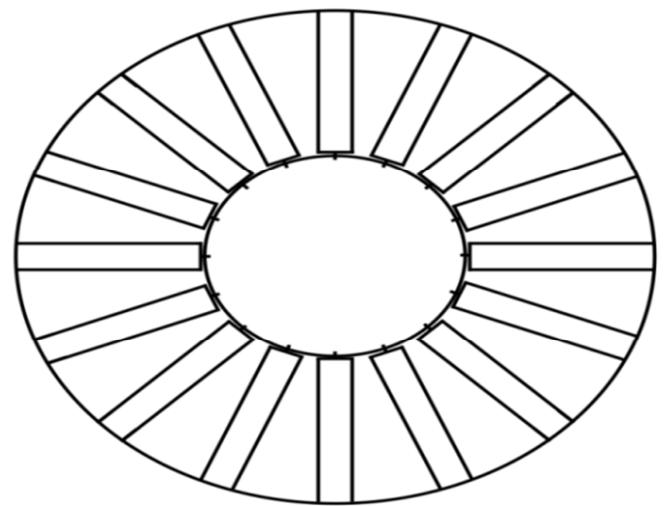

Fig. 6. The second circle is a $5 \mathbf{m m}$ diameter iron wire. The circumference of the circle is about $270 \mathrm{~cm}$. The circumference is divided into 16 parts. Each part is fixed with a $3 \mathrm{~mm}$ wire in the shape of a rectangle $(5 \mathrm{~cm} \times 25 \mathrm{~cm})$, for place the comb inside this rectangle, this circle is fixed in the moving chassis at a height of $41 \mathrm{~cm}$ from the first circle, and the ends of the rectangles is fixed with a small circle from wire. 


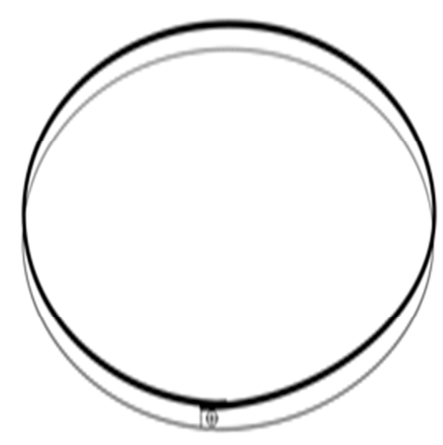

Fig. 7. The third circle (thickness $5 \mathrm{~mm} \times 18 \mathrm{~mm}$ width), thickness $5 \mathrm{~mm}$ to upper and circumference 145 cm and its center is the same center of the extractor, to carry the comb end down, the width of this circle $18 \mathrm{~mm}$ is higher than the width of the first circle $15 \mathrm{~mm}$ until the comb is slightly oblique towards the extractor wall.

Second : - Evaluation the time with minutes: -

The temporary modify of honey extractor with moving baskets to radial extractor while retaining all components and parts of the extractor: -

A- Comparison among the time of extracting a batch of honeycombs (eight combs), before modification and after this the temporary modification, and the radial extractor ( 8 combs ) for each of : -

1 - The extractor with moving baskets.

2 - Temporary modified extractor by iron wire letter $n$.

3 - The radial extractor (8 combs).

B - Comparison between the time for extracting 16 combs by each of:-

1 - The radial extractor (8 combs).

2 - The radial extractor (16 combs).

3 - The radial extractor without baskets (16 combs).

Third:The numbers of extracted honeycombs per hour:-

A- Comparison among the numbers of extracted honeycombs per hour (all extractors are 8 combs) for each of : -

$1-$ The extractor with moving baskets.

2 - Temporary modified extractor by iron wire letter $n$.

3 - The radial extractor (8 combs).

B - Comparison between the numbers of extracted honeycombs per hour for extracting 16 combs by each of:-

1 - The radial extractor ( 8 combs).

2 - The radial extractor (16 combs).

3 - The radial extractor without baskets (16 combs).

Fourthly:Evaluation broken combs and intact (unbroken) combs after extracting and percentage:-

A: Comparison between the numbers of broken combs after extracting and percentage for each of :-

1- The extractor with moving baskets ( 8 combs).

2- The radial extractor ( 8 combs).

B:Comparison between the numbers of intact (unbroken) combs after extracting and percentage for each of:-

1- The extractor with moving baskets ( 8 combs).

2- The radial extractor (8 combs).
Fifthly:- Evaluation broken combs and intact (unbroken) combs after extracting for the radial extractor $(8$ combs) with method of placing the comb head beside the moving axis of the basket, or reverse this situation, and percentage for each of them:-

Comparison between broken combs and percentage in the following:-

1- Method of placing the comb head beside the moving axis of the basket (outward direction) and percentage for it, (m. outward direction).

2- Method of placing the comb head is reversed the former situation (inward direction) and percentage for it, (m. inward direction).

Sixthly: - Statistical analysis of data:

All data were statistically analyzed by Duncan's Multiple Range Test as described by Duncan (1955).Test and L.S.D. value at 0.05 . All the obtained results were statistically analyzed according to analysis of data variance. The proper " $F$ " and L.S.D. values were calculated according to Snedecor and Cochran (1967). The computer program for that was Statistical Package for the Social Sciences (SPSS).

\section{RESULTS AND DISCUSSION}

First: - Evaluation the time with minutes: -

The temporary modify of honey extractor with moving baskets to radial extractor while retaining all components and parts of the extractor: -

Noticeable: The lower the time is the best, during honey extraction.

A - Comparison among the time of extracting a batch of honeycombs (8 combs), before modification and after this the temporary modification, and the radial extractor (8 combs) for each of: -

1 - The extractor with moving baskets.

2 - Temporary modified extractor by iron wire letter $n$.

3 - The radial extractor ( 8 combs).

The statistical analysis of data obtained in Table (1) and Fig. (8) showed that:-

There were highly significant differences for the time between the extractor with moving baskets and each of temporary modified extractor by iron wire letter $n$ and the radial extractor ( 8 combs), where the averages were $9.25 \mathrm{c} \pm 0.30,5.13 \mathrm{~b} \pm 0.30$ and $4.00 \mathrm{a} \pm 0.26$, respectively.

Table 1. Comparison among the time of each of:1 - The extractor with moving baskets.

2 - Temporary modified extractor by iron wire letter $n$. 3 - The radial extractor ( 8 combs).

\begin{tabular}{lccc}
\hline & Average & $\begin{array}{c}\text { standard } \\
\text { deviation }\end{array}$ & Average \\
\hline 1 & $9.25 \mathrm{c}$ & 0.30 & $9.25 \mathrm{c} \pm 0.30$ \\
2 & $5.13 \mathrm{~b}$ & 0.30 & $5.13 \mathrm{~b} \pm 0.30$ \\
3 & $4.00 \mathrm{a}$ & 0.26 & $4.00 \mathrm{a} \pm 0.26$ \\
\hline LSD & & & 0.40 \\
\hline
\end{tabular}

Values followed by the same letter are not significantly different at the $5 \%$ level of probability

There is also little significant difference between temporary modified extractor by iron wire letter $n$ and the radial extractor ( 8 combs), where the averages were $5.13 \mathrm{~b}$ \pm 0.30 and $4.00 \mathrm{a} \pm 0.26$, respectively. 
The best were the radial extractor ( 8 combs), then temporary modified extractor by iron wire letter $n$, where time was half time, approximately of the extractor with moving baskets.

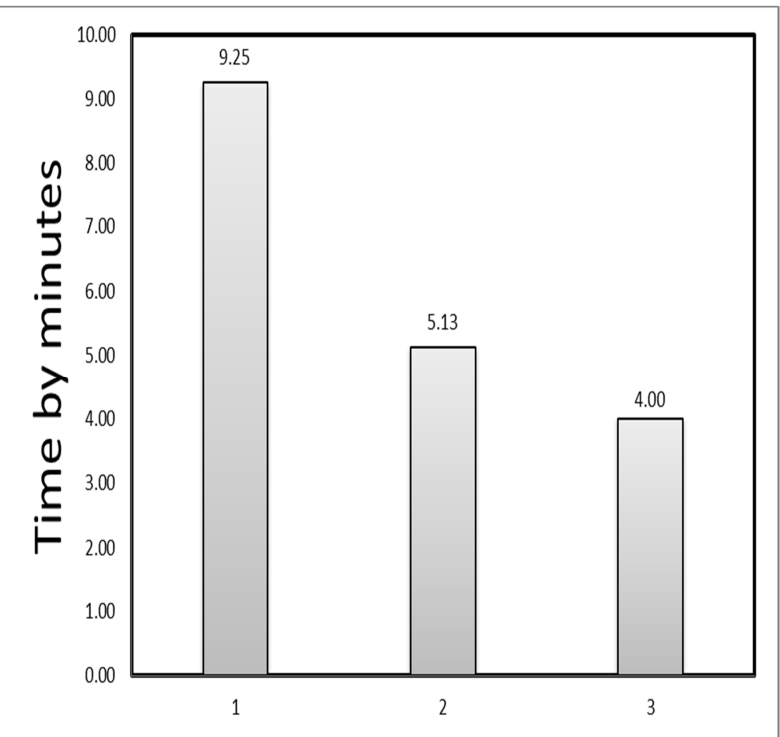

Fig. 8. Comparison among the time of each of:-

1 - The extractor with moving baskets.

2 - Temporary modified extractor by iron wire letter $n$.

3 - The radial extractor (8 combs).

B - Comparison between the time for extracting 16 combs by each of:-

1 - The radial extractor (8 combs).

2 - The radial extractor (16 combs).

3 - The radial extractor without baskets (16 combs).

The statistical analysis of data obtained in Table (2) and Fig. (9) showed that: -

There were highly significant differences for the time between the radial extractor ( 8 combs) and the radial extractor without baskets (16 combs), where the averages were $8.0 \pm 0.53$ and $4.3 \mathrm{a} \pm 0.18$ respectively also, there were highly significant differences for the time between the radial extractor ( 8 combs) and the radial extractor (16 combs), where the averages were $8.0 \pm 0.53$ and $4.5 \pm 0.17$ respectively.

The best were the radial extractor without baskets (16 combs) and the radial extractor (16 combs) than the radial extractor ( 8 combs), where time was half time, approximately of the radial extractor ( 8 combs).

Table 2. Comparison between the time for extracting 16 combs by each of:-

1 - The radial extractor ( 8 combs).

2 - The radial extractor (16 combs).

3 - The radial extractor without baskets ( 16 combs).

\begin{tabular}{cccc}
\hline & Average & $\begin{array}{c}\text { standard } \\
\text { deviation }\end{array}$ & Average \\
\hline 1 & $8.0 \mathrm{~b}$ & 0.53 & $0.53 \pm 8,0 \mathrm{~b}$ \\
2 & $4.5 \mathrm{a}$ & 0.17 & $0.17 \pm \mathrm{a} 4.5$ \\
3 & $4.3 \mathrm{a}$ & 0.18 & $0.18 \pm \mathrm{a} 4.3$ \\
\hline & LSD & & 0.46
\end{tabular}

Values followed by the same letter are not significantly different at the $5 \%$ level of probability.

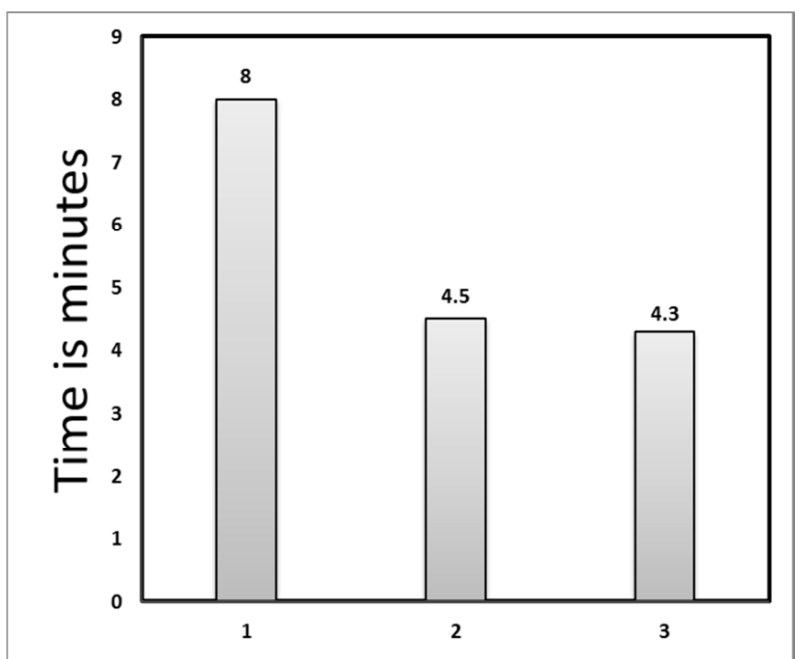

Fig. 9. Comparison between the time for extracting 16 combs by each of:-

1 - The radial extractor $(8 \mathrm{combs})$.

2 - The radial extractor (16 combs).

3 - The radial extractor without baskets (16 combs).

Second: The numbers of extracted honeycombs per hour:-

A - Comparison among the numbers of extracted honeycombs per hour (all extractors are 8 combs) for each of : -

1 - The extractor with moving baskets.

2 - Temporary modified extractor by iron wire letter $n$.

3 - The radial extractor ( 8 combs).

The statistical analysis of data presented in Table (3) and illustrated in Fig. (10) showed that :

There were highly significant differences for the numbers of extracted honeycombs per hour between the extractor with moving baskets and each of temporary modified extractor by iron wire letter $\mathrm{n}$ and the radial extractor ( 8 combs), where the averages were $51.94 \pm 1.69$, $93.76 \pm 5.44$ and $120.42 \pm 7.96$, respectively.

There is also little significant difference between temporary modified extractor by iron wire letter $\mathrm{n}$ and the radial extractor ( 8 combs), where the averages were 93.76 \pm 5.44 and $120.42 \pm 7.96$, respectively.

The best were the radial extractor ( 8 combs), then temporary modified extractor by iron wire letter $n$, where the numbers of extracted honeycombs per hour for them were double, approximately the numbers of extracted honeycombs per hour of the extractor with moving baskets.

Table 3. Comparison among the numbers of extracted honey combs per hour (all extractors are 8 combs) for each of:-

1 - The extractor with moving baskets.

2 - Temporary modified extractor by iron wire letter $\mathbf{n}$. 3 - The radial extractor ( 8 combs).

\begin{tabular}{cccc}
\hline & Average & $\begin{array}{c}\text { standard } \\
\text { deviation }\end{array}$ & Average \\
\hline 1 & $51.94 \mathrm{c}$ & 1.69 & $51.94 \mathrm{c} \pm 1.69$ \\
2 & $93.76 \mathrm{~b}$ & 5.44 & $93.76 \mathrm{~b} \pm 5.44$ \\
3 & $120.42 \mathrm{a}$ & 7.96 & $120.42 \mathrm{a} \pm 7.96$ \\
\hline \multicolumn{5}{c}{ LSD } & 11.58
\end{tabular}

Values followed by the same letter are not significantly different at the $5 \%$ level of probability. 


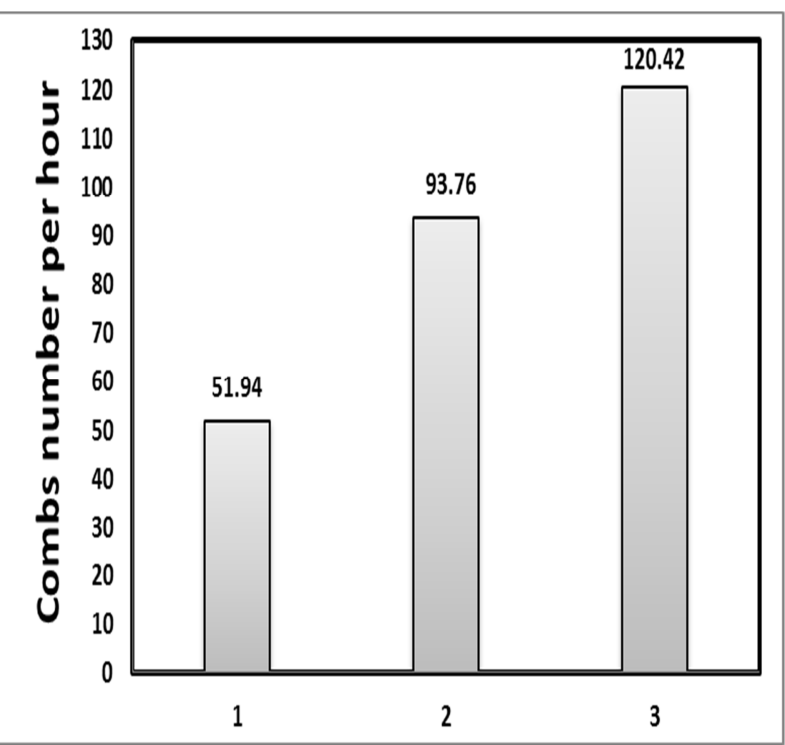

Fig. 10. Comparison among the numbers of extracted honey combs per hour (all extractors are 8 combs) for each of:-

1 - The extractor with moving baskets.

2 - Temporary modified extractor by iron wire letter $n$.

3 - The radial extractor (8 combs).

B - Comparison between the numbers of extracted honey combs per hour for extracting 16 combs by each of:-

1 - The radial extractor ( 8 combs).

2 - The radial extractor (16 combs).

3 - The radial extractor without baskets ( 16 combs).

The statistical analysis of data obtained in Table (4) and Fig. (11) cleared that: -

There were highly significant differences for the numbers of extracted honey combs per hour between the radial extractor ( 8 combs) and the radial extractor without baskets (16 combs), where averages were $120.42 \pm$ 7.96 and $223.59 \pm 9.84$ respectively, also, there were highly significant differences for the numbers of extracted honey combs per hour between the radial extractor $(8$ combs) and the radial extractor (16 combs), where averages were $120.42 \pm 7.96$ and $213.57 \pm 7.91$ respectively.

The best were the radial extractor without baskets (16 combs ) and then the radial extractor (16 combs) and in the end, the radial extractor ( 8 combs), where the numbers was double, approximately the numbers of the radial extractor (8 combs).

Table 4. Comparison between the numbers of extracted honey combs per hour for extracting 16 combs by each of:-

1 - The radial extractor ( 8 combs).

2 - The radial extractor (16 combs).

3 - The radial extractor without baskets (16 combs).

\begin{tabular}{lccc}
\hline & Average & $\begin{array}{c}\text { standard } \\
\text { deviation }\end{array}$ & Average \\
\hline 1 & $120.42 \mathrm{~b}$ & 7.96 & $120.42 \mathrm{~b} \pm 7.96$ \\
2 & $213.57 \mathrm{a}$ & 7.91 & $213.57 \mathrm{a} \pm 7.91$ \\
3 & $\mathrm{a} 223.59$ & 9.84 & $223.59 \mathrm{a} \pm 9.84$ \\
\hline \multicolumn{5}{c}{ LSD } & & 11.58 \\
\hline
\end{tabular}

Values followed by the same letter are not significantly different at the $5 \%$ level of probability.

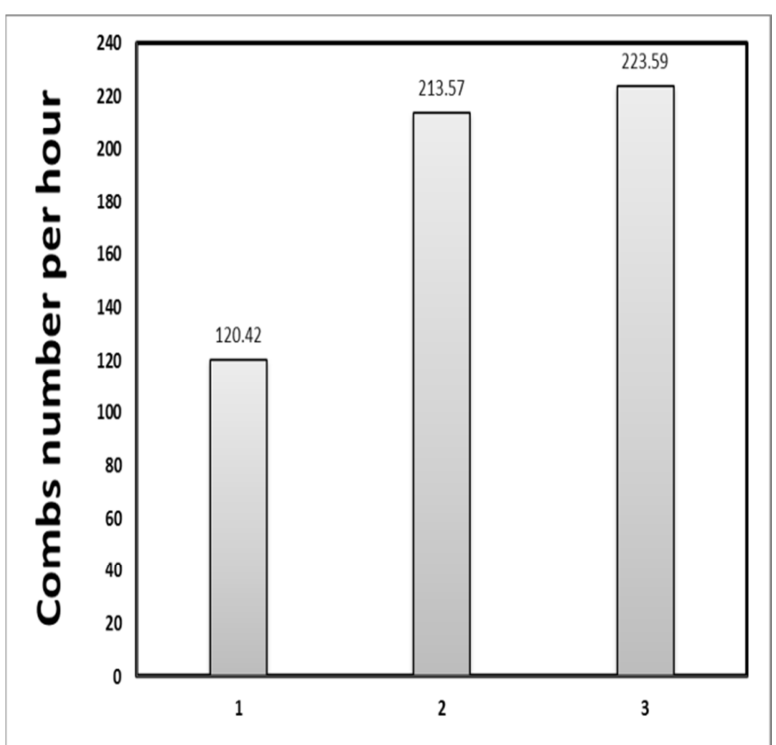

Fig. 11. Comparison between the numbers of extracted honey combs per hour for extracting 16 combs by each of:-

1 - The radial extractor (8 combs).

2 - The radial extractor (16 combs).

3 - The radial extractor without baskets (16 combs).

Third: Evaluation broken combs and intact (unbroken) combs after extracting and percentage:-

A: Comparison between the numbers of broken combs after extracting for each of:-

1- The extractor with moving baskets ( 8 combs).

2- The radial extractor ( 8 combs).

The statistical analysis of data obtained in Table (5) and Fig. (12) revealed that: -

There were highly significant differences for the numbers of broken combs after extracting between the extractor with moving baskets ( 8 combs) and the radial extractor ( 8 combs), where the averages were $5 \pm 0.71$ and $0 \pm 0.00$ respectively, and percentage were $62.5 \%$ and 0 $\%$ respectively.

The best were the radial extractor ( 8 combs), where there are no any broken combs. The extractor with moving baskets ( 8 combs) there are 5 broken combs from 8 combs, percentage was $62.5 \%$ broken combs.

B: - Comparison between the numbers of intact (unbroken) combs after extracting for each of:-

1 - The extractor with moving baskets ( 8 combs).

2- The radial extractor (8 combs).

Table 5. Comparison between the numbers of broken combs after extracting for each of:-

1- The extractor with moving baskets ( 8 combs).

2- The radial extractor (8 combs).

\begin{tabular}{cccc}
\hline & Average & $\begin{array}{c}\text { standard } \\
\text { deviation }\end{array}$ & Average \\
\hline 1 & $5 \mathrm{~b}$ & 0.71 & $5 \mathrm{~b} \pm 0.71$ \\
2 & $0 \mathrm{a}$ & 0.00 & $0 \mathrm{a} \pm 0.00$ \\
\hline \multicolumn{5}{c}{ LSD } & & 0.73 \\
\hline
\end{tabular}

$\overline{\text { Values followed by the same letter are not significantly different at the }}$ $5 \%$ level of probability. 


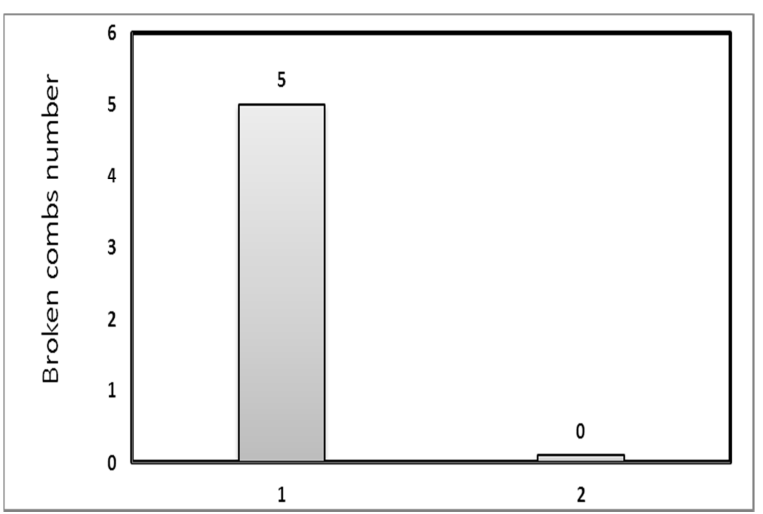

Fig. 12. Comparison between the numbers of broken combs after extracting for each of:-

1- The extractor with moving baskets $(8$ combs).

2- The radial extractor (8 combs).

The statistical analysis of data obtained in Table (6) and Fig. (13) showed that: -

There were highly significant differences for the numbers of intact (unbroken) combs after extracting between the extractor with moving baskets ( 8 combs) and the radial extractor ( 8 combs), where the averages were $3 \mathrm{~b}$ \pm 0.71 and $8 \mathrm{a} \pm 0.00$ respectively, and percentage were $37.5 \%$ and $100 \%$ respectively.

The best were the radial extractor ( 8 combs), where there are no any broken combs, percentage was $100 \%$ intact (unbroken). The extractor with moving baskets (8 combs) there are 3 intact (unbroken) combs from 8 combs, percentage was $37.5 \%$ intact (unbroken) combs.

Table 6. Comparison between the numbers of intact (unbroken) combs after extracting for each of:-

1- The extractor with moving baskets ( 8 combs).

2- The radial extractor (8 combs).

\begin{tabular}{rrrr}
\hline & Average & $\begin{array}{r}\text { standard } \\
\text { deviation }\end{array}$ & Average \\
\hline 1 & $3 \mathrm{~b}$ & 0.71 & $3 \mathrm{~b} \pm 0.71$ \\
2 & $8 \mathrm{a}$ & 0.00 & $8 \mathrm{a} \pm 0.00$ \\
\hline & & LSD & 0.73 \\
\hline
\end{tabular}

Values followed by the same letter are not significantly different at the $5 \%$ level of probability.

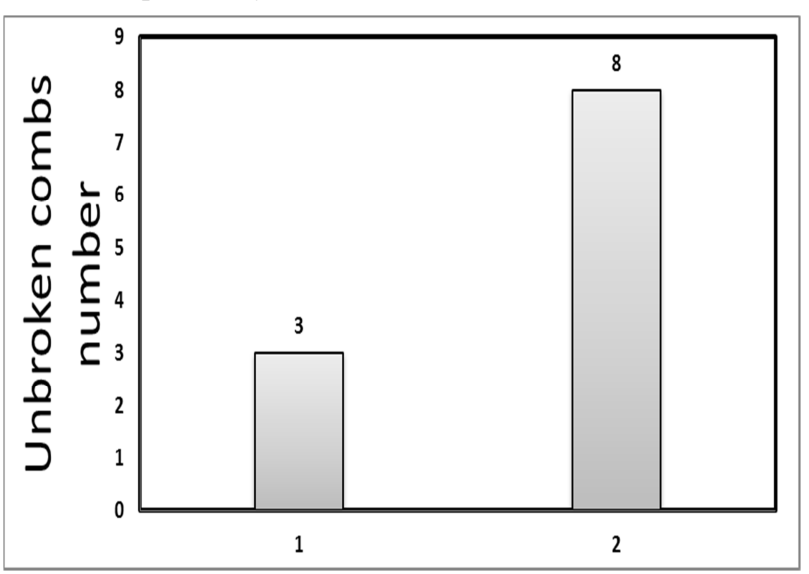

Fig. 13. Comparison between the numbers of intact (unbroken) combs after extracting for each of:-

1- The extractor with moving baskets ( 8 combs).

2- The radial extractor $(8$ combs).
Fourthly:- Evaluation broken combs and intact (unbroken) combs after extracting for the radial extractor $(8$ combs) with method of placing the comb head beside the moving axis of the basket, or reverse this situation, and percentage for each of them:-

Comparison between broken combs in the following two methods:-

1- Method of placing the comb head beside the moving axis of the basket (outward direction) and percentage for it, (m. outward direction).

2- Method of placing the comb head is reversed the former situation (inward direction) and percentage for it, ( $\mathrm{m}$. inward direction).

The statistical analysis of data presented in Table (7) and illustrated in Fig. (14) cleared that: -

There were highly significant differences for the numbers of broken combs after extracting between the methods (1- m. outward direction). and the method (2- $\mathrm{m}$. inward direction)., where the averages were $0 \pm 0.00$ and 8 \pm 0.00 respectively, and percentage of broken combs were $0 \%$ and $100 \%$ respectively.

Table 7. Comparison between broken combs in the following two methods:-

1- Method of placing the comb head beside the moving axis of the basket (m. outward direction).

2- Method of placing the comb head is reversed the former situation (m. inward direction).

\begin{tabular}{cccc}
\hline & $\begin{array}{c}\text { Broken } \\
\text { average }\end{array}$ & $\begin{array}{c}\text { standard } \\
\text { deviation }\end{array}$ & Average \\
\hline 1 & 0.00 & 0 & $0 \mathrm{a} \pm 0.00$ \\
2 & 8.00 & 0 & $8 \mathrm{~b} \pm 0.00$ \\
\hline \multicolumn{4}{c}{ LSD } \\
\hline
\end{tabular}

$\overline{\text { Values followed by the same letter are not significantly different at the }}$ $5 \%$ level of probability.

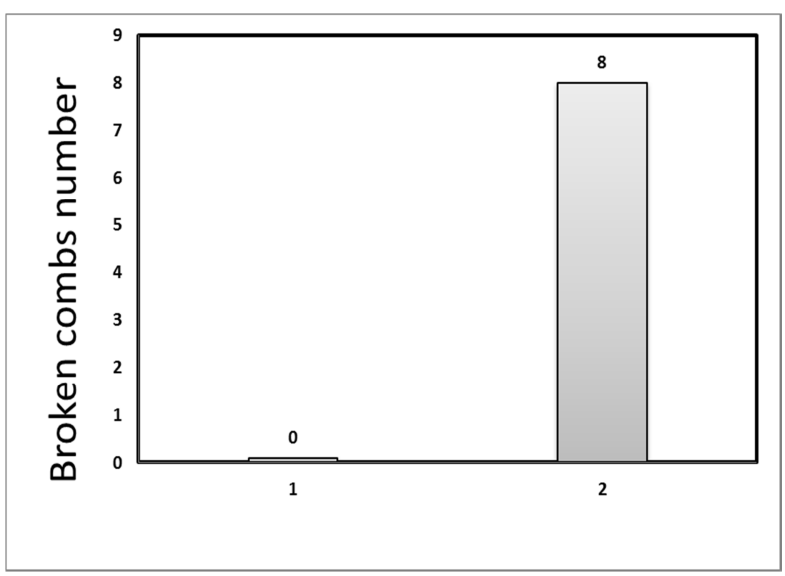

Fig. 14. Comparison between broken combs in the following two methods

1- Method of placing the comb head beside the moving axis of the basket (m. outward direction) and percentage for it.

2- Method of placing the comb head is reversed the former situation (m. inward direction) and percentage for it.

The best methods was the first method of placing the comb head beside the moving axis of the basket ( $\mathrm{m}$. outward direction), where that all combs were intact 
(unbroken), while the second method was all the combs were broken, there are no intact (unbroken) combs.

Explanation: - the hexagonal cells in the honeycomb tend to rise at an angle of 14 degrees upward the comb head direction, this situation facilitates the exit of honey through the air coming from the center of extractor to the wall, in this situation, the air is emptied in front of the hexagonal cells and the honey is released easily so do not break the honey combs. It is recommended to use this simple and inexpensive method to modify the extractor with moving baskets to the radial extractor while retaining all parts and components of the collection as follows:

It is recommended to use the modified extractor to radial extractor without baskets (16 combs) because it is very light, also the radial extractor with baskets (16 baskets) especially in large apiaries because its provide about four times the time of extractor with moving baskets, and there is no broken combs.

As well as to use the radial extractor ( 8 combs) because it provides more than twice the time of the extractor with moving baskets, and there is no broken combs.

As well as to use the temporary modify extractor with the letter n, especially in the small apiaries and cost-free and because it provides about twice the time of the extractor with moving baskets ( 8 combs), and there is no broken combs.

It is recommended to use this the modify of honey extractor with moving baskets to radial extractor while retaining all components and parts of the extractor for:-

1 - Exploitation of the available extractor, which is found at most beekeepers, it is the extractor with moving baskets.

2 - The modification cost is too little.

3 - Retention and keeping of all parts and components of extractor as it.

4 - Do not break any combs, whether new or have a pollen, as in the case of the extractor with moving combs.

5 - Do not stop turning and roll combs or baskets to extracting the other side of the combs.

6 - The both two sides of the combs are extracted once at the same time.

7 - This radial extractor is easy to jaw and the installation while all anther the radial extractors are fixed by welding and very heavy.
8 - When transferring the extractor can be dismantled and go out these baskets and parts then it becomes light.

9 - Easy to go out baskets and cleaned out its as well as easy cleaning most parts of the extractor.

10 - Collecting between all the advantages of the extractor with moving baskets and the advantages of radial extractor.

11 - The best using the extractor without baskets ( 16 combs) because it is very light, it provides more four times the time of the extractor with moving baskets.

12 - When the same number baskets of the extractor with moving baskets after this modify are used, it provides twice double times.

13 - When using double baskets, it provides four times the time of the extractor with moving baskets.

14 - Providing effort and energy as well as providing time which is the most important thing during the extracting.

\section{REFERENCES}

Abdellatif, M.A.(1994). Bee World (In Arabic). Fac. Of Agric. Alexandria Univ., (685) Dar El-Maarifah Alexandria, Egypt.

El-Ansuaary, O.M.N.(2007). The Bees Encyclopedia for honey production and the crops pollination (In Arabic). Fac. Agric. Alexandria Univ., Egypt, 1460 Page.

El-Banby, M.A.(1994). Honey bees and its productivity (In Arabic). Fac. Agric., Ain Shams Univ., pp. 378, Dar El-Maarif, Egypt.

Duncan, B.D. (1955). Multiple Range and Multiple F. test Biometrics, 11: 1-42.

Hassan,A.R. and A.M.Aly(1997): Effect of honey extracting manner on longevity, behavior and production capacity of honeybee workers (Apis mellifera L.) in Egypt. Proc. $1^{\text {st }}$ Conf. Agric. Sci., Assiut Univ., Vol. II, 749-758.

Hassanein, M.H.(1960). "Bees Kingdom" (In Arabic). Anglo Egyptian Libray, Cairo, UAR (449).

Hussein, M.H. (2004). Honey Bee Encyclopedia, (In Arabic). Fac. Of Agric. Assiut Univ., 1328 page,

Snedecor, W.G. and G.W. Cochran (1967). Statistical Methods. Iowa State Univ. Press. Ams, USA. 6th ed. PP. 393.

Wafa, A.K. (1959). Beekeeping and honey-Bees. (In Arabic). Anglo Egyptian Library, Cairo UAR (387).

\footnotetext{
طريقة بسيطة وغير مكلفة لتعديل الفراز القلاب لعسل النحل إلى فراز شعاعي سهل الفك والتركيب أو بدون سلال

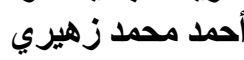
قسم بحوث النحل ـ معهد بحوث وقاية النباتات ـ مركز البحوث الزراعية - وزارة الزراعة.

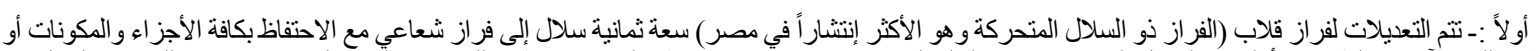

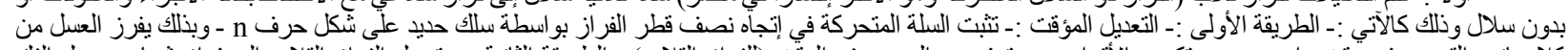

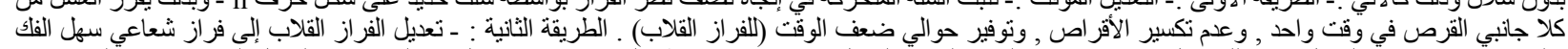

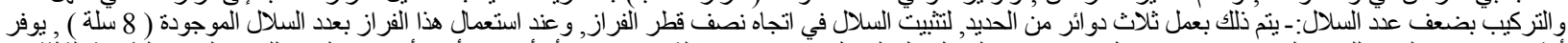

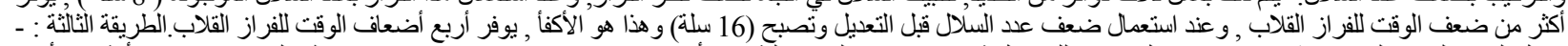

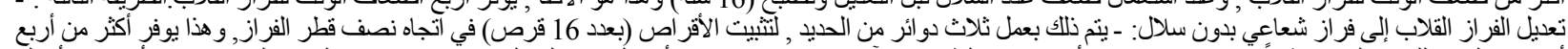

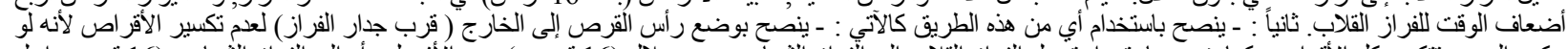

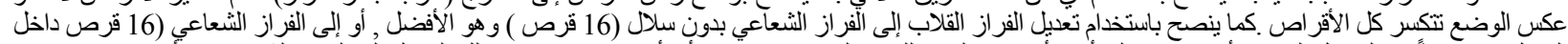

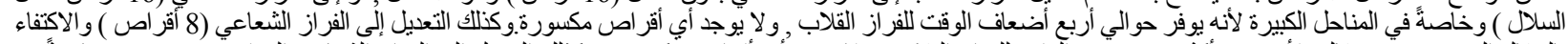

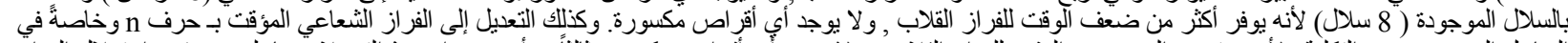

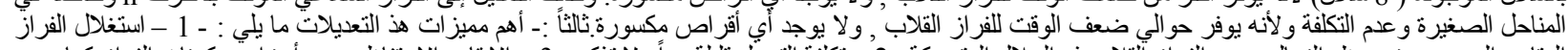

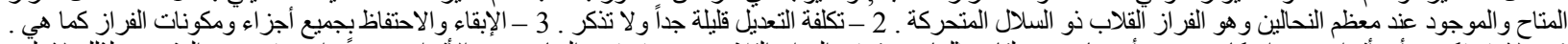

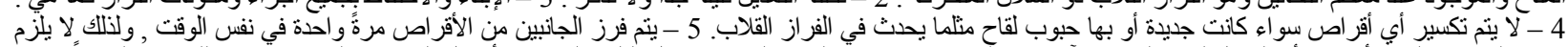

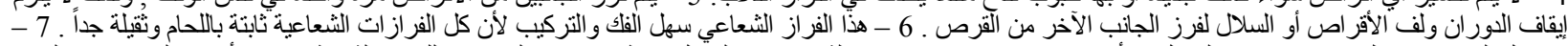

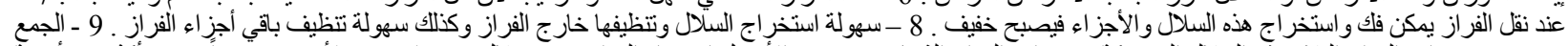

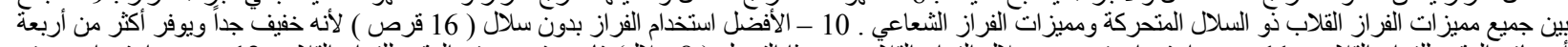

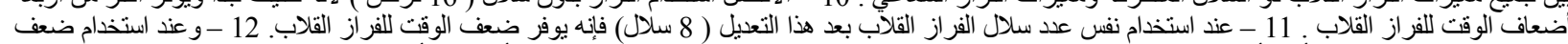

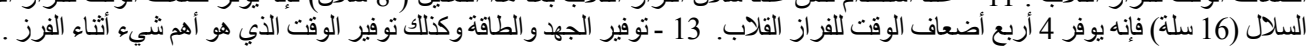

